\title{
Problems of High Tension Overhead Electric Supply Systems.
}

$\mathrm{T}$

HE setting up of high tension overhead electric supply systems all over Great Britain has brought to the foreground many engineering and scientific problems, the solutions of which are urgently wanted. One is the best design for insulators so as to avoid flashover, and another is the best way of preventing the vibrations of overhead transmission conductors. In a paper read by Mr. P. J. Ryle to the Institution of Electrical Engineers on Feb. 5, both these problems were discussed and partial solutions given.

Seven years ago, the Newcastle Electric Supply Co. put into operation a 66-kilovolt line which is now nearly a hundred miles long. It was soon found out that flashovers occurred in the strings of suspended insulators in industrial areas. It was also discovered that they occurred oftener when the line was near a rocky coast than when it was in the neighbourhood. of a sandy beach. Probably the salt spray was the cause. The number of insulators in the supports was increased from five to six ; but this had little effect. The main cause was traced to the deposits on the insulators. Similar troubles have occurred in Germany near lignite (brown coal) power stations, and mention was made of a complete 110-kilovolt system which had to be roofed over owing to the dust from an adjacent lignite station. Deposition on the porcelain surfaces is favoured by hollows in the insulator which are protected from the wind and rain. Several firms in Great Britain have installed fog and dirt chambers for the purpose of carrying out full voltage tests on these insulators, under the most severe conditions. The solution favoured is that facilities should always be available for shutting down main transmission lines once a year for a thorough inspection and for the cleaning of the insulators. This could be done at a period of light load.
Vibration probably occurs on every transmission line in the world; but breakdowns due to it do not often occur. In Mr. Ryle's paper the swaying of the conductor as a whole, which is evident in a strong wind, was not discussed, nor was the 'dancing' of conductors which sometimes occurs when rapid changes in the load or the temperature occur. He dealt with phenomena analogous to the humming of telephone and telegraph wires, the transverse vibration of aeroplane stay-wires which caused difficulty in the early days of flying, the regular swaying of tall factory chimneys across the wind, and the vibration of underwater towing cables. The 'speed-wobble' on motor cycles, which is due to the front and rear halves of the front wheel tending to vibrate in opposite directions, is probably due to a similar cause.

The cause of the vibration, which is, at least initially, in the plane perpendicular to the direction of the wind, is attributed to the instability of a type of air flow in the wake of a cylindrical body. The eddies seem to set up alternating forces transverse to the wind, which tend to initiate and maintain vibration, especially when their period coincides with a natural period for transverse vibration. Little is known at present of the various types of damping forces due to the air, elastic hysteresis in the wires and in the lattice towers. Luckily, there is, in general, little probability of vibrations ever building up to large amplitudes, as a very slight change in the wind velocity alters the resonant harmonic. Experience has shown that the vibrations increase the larger the conductor and the more tightly it is strung. Wind velocities of between two and twenty miles per hour are the most effective in producing these vibrations. Some guiding principles were given for the design of damping devices.

\section{Indian Lac Research.}

THHE Annual Report (to Mar. 31, 1930) of the Indian 1 Lac Association for Research gives evidence that the important work carried on at this Institute is making steady progress. The Institute and its connecting buildings are almost completed, and the staff, which now numbers 24 , has had added to it $\mathrm{Dr}$. R. W. Aldis, in charge of the physico-chemical section. As the director and bio-chemist, Mrs. Dorothy Norris, states, "it will now be possible to examine closely each stage of the ordinary process of lac manufacture, with a view to checking waste and devising improvements"

For those interested in lac and its development and economics this report will well repay a study. Briefly, the work at the Institute resolves itself into the following main features: The formation of plantations of species of trees which are considered likely to produce the largest amount of lac. The chief factors under study are $(a)$ the sylviculture and requirements in soils, etc., of the different species and their success under varying climatic conditions; $(b)$ the success attainable by employing manures in the plantations; (c) the chemical factors affecting or encouraging the growth of the trees on different soils ; $(d)$ the chemical differences in the sap of the twigs and their influence on the lac insect itself ; $(e)$ the seasonal variations in host plants of the lac insect, also under investigation in the laboratories of the bio-chemist and assistants, together with analysis work of lac obtained from different host plants.

The other important section of the Institute is that on entomology, under Mr. P. M. Glover, helped by a staff of nine. Mr. Glover divides the work of his branch into two groups - first, the bionomics of the lac insect, Laccifer (Tachardia) lacca, and secondly, the investigation of the insect enemies and friends of the lac insect, the latter including the enemies of lac. host trees. It is impossible to follow Mr. Glover in the interesting account of the problems with which he is faced. As an example it will be sufficient to state that one well-known lepidopterous (Noctuidæ) pest, Eublemma amabilis, passes through six lifecycles in a year and eight days, to indicate the complications which insect depredators add to the study of this valuable lac insect and its habits, and to the best methods of propagation and so forth. The theory that ants preyed upon the lac insect and consequently diminished the crop is now officially disproved in the majority of cases investigated.

That the work of the entomological branch, however, is of the greatest importance is supported by Mr. Glover's statement on the damage done by pests: "The annual stick lac production of India, including Burma and Assam, is in the neighbourhood of $1,700,000$ of maunds [ 1 maund $=80 \mathrm{lb}$.] valued at about Rs.6,80,00,000. The average percentage damage by insects to lac crops is 60 per cent ; this means that the annual lac crop is roughly one-third of the hypothetical undamaged crop, giving an annual loss due to insect damage of Rs.13,60,00,000." It will be apparent that the study of the pests of lac and methods of combating them should well repay the sums expended on the research undertaken with this object in view.

No. 3199, VoL. 127] 